\title{
Korean Vocabulary Learning Strategies of University Students in Thailand
}

\author{
Yurim Lee ${ }^{1}$ and Sayamon Sornsuwannasri ${ }^{2^{*}}$ \\ ${ }^{1}$ Faculty of International Korean Language and Culture, Kyung Hee \\ University, Republic of Korea \\ ${ }^{2}$ Division of Korean, Department of Eastern Languages, Faculty of \\ Humanities, Chiang Mai University, Chiang Mai 50200, Thailand \\ ${ }^{*}$ Corresponding author. E-mail: sayamon.sorn@elearning.cmu.ac.th \\ https://doi.org/10.12982/CMUJASR.2018.0004
}

\section{ABSTRACT}

This research aims to investigate trends in the use of Korean language vocabulary learning strategies by Thai students and the relationship between students' use of vocabulary learning strategies and their specific characteristics. Participants comprised Thai students currently studying the Korean language. Data were collected through a questionnaire, examined for reliability, and then analyzed. The first step in data analysis was to explore trends in the students' use of vocabulary learning strategies, which could be categorized into two types, namely vocabulary discovery strategies and vocabulary consolidation strategies. A one-way analysis of variance (ANOVA) was conducted using SPSS 24 in order to determine statistically significant differences between the two types of strategy as well as the frequencies of use of each strategy. Next, correlation analysis was performed via SPSS 24 to assess the relationship between the students' Korean language vocabulary learning strategies and their specific characteristics (i.e. gender, age, level of Korean language proficiency, experience in residing in Korea, length of Korean language study, experience in traveling/undertaking training in Korea, and state of being of Korean descent). From the analysis, it has been discovered that Thai students employed both discovery and consolidation strategies concurrently, yet consolidation strategies were used more frequently than the other. The most frequently used strategy was "If [I] cannot think of certain words when speaking or writing in Korean, [I] refer to the Internet or 
a dictionary". Besides, statistical significance has been found in the relationship between vocabulary learning strategies and Korean language proficiency, while consolidation strategies were observed to correlate with the students' gender. The findings of this research would therefore enable teachers to recognize crucial elements of Korean vocabulary pedagogy, also allowing them to adjust their teaching so as to correspond with students' different levels of language proficiency.

Keywords: Vocabulary learning, Vocabulary learning strategies, Thai students learning Korean language, Learners' specific characteristics

\section{INTRODUCTION}

When learning a foreign language, vocabulary and grammar are crucially important elements that learners need to acquire. In developing language acquisition, it is imperative for learners to study grammatical rules and their applications as well as syntax of the target language thoroughly in order to be able to construct well-formed and correct sentences. In addition to a good knowledge of grammar, the ability to utilize diverse, appropriate and pertinent vocabularies is also essential as effective communication cannot take place if learners only know how to execute grammar but cannot figure out the right words to convey their message.

For Thai native speakers, learning vocabularies in foreign languages especially in Korean, which belongs to a different language family from the Thai language, can be considerably difficult because of differences in the two languages' morphology and phonology. In this connection, memorization is seen as an unavoidable mean that Thai students learning the Korean language at a fundamental level seek to employ. However, apart from memorization, there are other factors and learning strategies that help learners recognize words effectively. For example, some specific characteristics of learners have also been found to contribute to better vocabulary learning. A thorough study in this regard is therefore needed so as to help create effective Korean vocabulary learning strategies for Thai students.

The objective of this is research is to answer two following research questions:

1. What are vocabulary learning strategies (i.e. vocabulary discovery strategies and vocabulary consolidation strategies) Thai university students employ in their vocabulary learning? 
2. Do Thai university students' specific characteristics (i.e. gender, age, level of Korean language proficiency, experience in residing in Korea, length of Korean language study, experience in traveling/ undertaking training in Korea, and being of Korean descent) have an impact on their use of vocabulary learning strategies?

\section{RELATED RESEARCH}

\section{Related research on language learning strategies for particular skills}

A considerable amount of research on language learning strategies with a focus on different skills has been published, some key examples of which are as follows:

A major research concerning speaking skills development in language learning strategies was conducted by Wang (2008), who studied the relationship between speaking learning strategies and the specific characteristics of Chinese university students majoring in the Korean language.

Studies focusing on listening skills in language learning strategies included researches by Sohn (2009), Yun (2013), Kim (2011), and Jeon \& Kuk (2017).

While a research by Kim (2011) and Jeon \& Kuk (2017) investigated a tendency of learners using language learning strategies to improve their listening skills, studies by Sohn (2009) and Yun (2013) examined the benefits of language learning strategiesand found that employing certain learning strategies could enhance learners' listening skills.

Researchers exploring language learning strategies for reading skills include Sawada (2006), Sim (2007), Ki (2009), Kim (2014), Lee (2016, 2017) and Baek (2017). Participants in their researches were foreign students such as Japanese, Chinese and American students.

Shin (2016) and Kang \& Kim (2016) conducted researches on writing skills-oriented language learning strategies among students studying the Korean language at the intermediate to the advanced levels.

Researches on language learning strategies that studied all the four skills belong to Ling (2016) and Lee et al. (2017). Data in this regard were collected from both domestic and international Korean language students.

The findings of the aforementioned researches reaffirm that language learning strategies indeed assist in the development of language skills. Since there is a notable lack of research concerning language learning strategies, especially vocabulary learning skills, 
that are based on Thai students, this research is therefore significant as it examined language learning strategies with an emphasis on vocabulary learning skills utilizing data collected from Thai students studying the Korean language.

\section{Related research on relationship between language learning strategies and learners' specific characteristics}

The following are related researches on the relationship between language learning strategies and learners' specific characteristics:

An initial research that explored the relationship between language learning strategies and learners' specific characteristics was a study by Kang (1999), which categorized students' specific characteristics by means of gender and native language.

A research by Won (2010) classified students' characteristics into gender, age, native language and cultural foundation. However, the last three categories were not found to correlate with the use of language learning strategies.

Shon (2011) specified students' characteristics by means of gender, experience in learning a foreign language, age and language proficiency. In research analysis, these factors were utilized as variables accordingly.

A research by Ling (2016) regarded a level of language proficiency as students' specific characteristics.

Kim (2016) based students' specific characteristics on gender, length of study, scores from a language proficiency test and grade point average. This research examined whether these specific characteristics correlate with the use of speaking strategies.

A research by Lee et al. (2017) investigated the relationship between: 1) gender and the use of listening strategies, 2) experience in studying a foreign language aboard and the use of reading strategies, and 3) native language and the use of writing strategies.

The above-mentioned set of research is observed to display a remarkable diversity of variables when examining the relationship between students' specific characteristics and the use of language learning strategies, using data collected mostly from students who studied the Korean language in Korea or Chinese students studying the Korean language. In line with this, the present research used the specific characteristics of Thai students studying the Korean language as variables and investigated the relationship between such variables and the use of language learning strategies with an emphasis on vocabulary learning skills. 


\section{RESEARCH METHODOLOGY}

\section{Research participants}

Data on Korean language vocabulary learning strategies employed by university students in Thailand were collected over a period of four months, starting from mid-February until the end of May 2018, through an on-line questionnaire. Participants in this research were students at a Thai university who either major or minor in Korean or take Korean as an elective course. The 63 participants consisted of seven (11.11\%) males and 56 (88.89\%) females aged between 19-27 years old, most of whom (90\%) were 19-22 years old. The participants were also required to assess their own level of Korean language proficiency, which were categorized into elementary, intermediate and advanced respectively, based on e.g. the length of their study and TOPIK scores. In this regard, the majority, 56 participants $(88.89 \%)$, rated themselves as being at the elementary level, while 6 participants $(9.52 \%)$ chose the intermediate level and one participant $(1.59 \%)$ was at the advanced level successively. Only five participants $(7.93 \%)$ had an experience in residing in Korea while 11 others $(17.46 \%)$ had an experience in traveling or undertaking training in Korea. The participants' length of Korean language study ranged from two months to seven years, with an average duration of 14 months. Three participants $(4.76 \%)$ were of Korean descent. The entire information of the participants was illustrated in the table below: 
Table 1. Demographic characteristics of questionnaire respondents.

\begin{tabular}{|c|c|c|c|}
\hline & & $\mathrm{n}=63$ & Percent (\%) \\
\hline \multirow{2}{*}{ Gender } & Male & 7 & 11.11 \\
\hline & Female & 56 & 88.89 \\
\hline \multirow{7}{*}{$\begin{array}{l}\text { Age } \\
\text { Average }=20.97 \text { years old }\end{array}$} & 19 years old & 11 & 17.46 \\
\hline & 20 years old & 16 & 25.40 \\
\hline & 21years old & 12 & 19.05 \\
\hline & 22 years old & 18 & 28.57 \\
\hline & 23 years old & 3 & 4.76 \\
\hline & 24 years old & 2 & 3.17 \\
\hline & 27 years old & 1 & 1.59 \\
\hline \multirow{3}{*}{ Level of Korean language proficiency } & Elementary & 56 & 88.89 \\
\hline & Intermediate & 6 & 9.52 \\
\hline & Advanced & 1 & 1.59 \\
\hline \multirow[b]{2}{*}{ Experience in residing in Korea } & With experience & 5 & 7.94 \\
\hline & No experience & 58 & 92.06 \\
\hline \multirow{17}{*}{ Length of Korean language study } & 2 months & 2 & 3.17 \\
\hline & 3 months & 4 & 6.34 \\
\hline & 4 months & 25 & 39.68 \\
\hline & 5 months & 3 & 4.76 \\
\hline & 6 months & 4 & 6.34 \\
\hline & 8 months & 1 & 1.59 \\
\hline & 10 months & 1 & 1.59 \\
\hline & 1 year & 5 & 7.94 \\
\hline & 1 year 3 months & 1 & 1.59 \\
\hline & 2 years & 5 & 7.94 \\
\hline & 2 years 4 months & 1 & 1.59 \\
\hline & 2 years 5 months & 1 & 1.59 \\
\hline & 2 years 6 months & 2 & 3.17 \\
\hline & 3 years & 5 & 7.94 \\
\hline & 4 years & 1 & 1.59 \\
\hline & 7 years & 1 & 1.59 \\
\hline & 7 years 1 month & 1 & 1.59 \\
\hline \multirow{2}{*}{$\begin{array}{l}\text { Experience in traveling/ } \\
\text { undertaking training in Korea }\end{array}$} & With Experience & 11 & 17.46 \\
\hline & No Experience & 52 & 82.54 \\
\hline \multirow{2}{*}{ Being of Korean descent } & Yes & 3 & 4.76 \\
\hline & No & 60 & 95.24 \\
\hline
\end{tabular}




\section{Research tools}

This research involved data collection on Korean language vocabulary learning strategies employed by students at a Thai university, together with an investigation into the relationship between learners' characteristics and such strategies. In this connection, students participating in the research were asked to sign a participation consent form and then answer a questionnaire, in which their personal information was included.

Next, the participants' demographic data were collected on gender, nationality, native language, age, level of Korean language proficiency, length of stay in Korea, length of Korean language study in Korea, length of Korean language study in Thailand, experience in traveling or undertaking training in Korea, and the state of being of Korean descent.

The questionnaire on vocabulary learning strategies utilized in this research was adapted from the Language Strategy Use Inventory by Cohen et al. (2002) and revised by Lee Yu Rim (Lee, 2016). A research by Lee (2016) applied the widely-referenced classification of vocabulary learning strategies suggested by Schmitt (Schmitt, 1997) along with Oxford's language learning strategies (Oxford, 1990) and based the questionnaire content regarding vocabulary usage on a research by Kang (2013). In this research, vocabulary learning strategies were categorized into two types, namely vocabulary discovery strategies and vocabulary consolidation strategies. This allowed better comprehensiveness and thoroughness than the questionnaire in Cohen, et al. (2002)'s Language Strategy Use Inventory. The questionnaire in this research was designed to effectively serve the purposes of the research and to best suit the participants' specific characteristics.

Initially drafted in Korean and then translated into Thai so as to be answered by Thai students, the questionnaire consisted of 83 questions related to vocabulary learning strategies. The strategies in these questions were categorized into two types: vocabulary discovery strategies and vocabulary consolidation strategies, and some questions with uncategorizable nature were included in both types. In this regard, 55 questions were grouped under the vocabulary discovery strategies; 50 under the vocabulary consolidation strategies; and 22 under both types. The frequency of their usage was classified into four levels, namely never, occasionally, somewhat frequently and very frequently. 
The following table shows samples of the 83 questions. These samples reflect the most frequently-used strategies among the students.

Table 2. Samples of questionnaire questions.

\begin{tabular}{|c|c|c|c|}
\hline No. & Question & $\begin{array}{l}\text { Vocabulary } \\
\text { discovery } \\
\text { strategy }\end{array}$ & $\begin{array}{l}\text { Vocabulary } \\
\text { consolidation } \\
\text { strategy }\end{array}$ \\
\hline 25 & $\begin{array}{l}\text { When exposed to an unfamiliar } \\
\text { word, I look up its meaning in a } \\
\text { dictionary. }\end{array}$ & O & \\
\hline 43 & $\begin{array}{l}\text { I watch Korean TV programs or } \\
\text { movies. }\end{array}$ & 0 & $\bullet$ \\
\hline 46 & $\begin{array}{l}\text { When someone speaks Korean, } \\
\text { I tend to listen to him/her carefully. }\end{array}$ & 0 & $\bullet$ \\
\hline 47 & $\begin{array}{l}\text { I look out for means to improve my } \\
\text { Korean language proficiency. }\end{array}$ & 0 & $\bullet$ \\
\hline 55 & $\begin{array}{l}\text { I give full concentration when } \\
\text { studying the Korean language. }\end{array}$ & 0 & $\bullet$ \\
\hline 61 & $\begin{array}{l}\text { When I cannot recall an exact word } \\
\text { while writing or speaking Korean, } \\
\text { I refer to the Internet or a dictionary. }\end{array}$ & & $\bullet$ \\
\hline 62 & $\begin{array}{l}\text { When I cannot recall an exact word } \\
\text { while writing or speaking Korean, } \\
\text { I consult my textbooks. }\end{array}$ & & 0 \\
\hline 64 & $\begin{array}{l}\text { I think the use of diverse and various } \\
\text { vocabulary is crucial when writing } \\
\text { or speaking Korean. }\end{array}$ & & $\bullet$ \\
\hline 67 & $\begin{array}{l}\text { I tend to feel anxious about using } \\
\text { proper vocabulary when writing or } \\
\text { speaking Korean. }\end{array}$ & & - \\
\hline 72 & $\begin{array}{l}\text { I would like to know how to } \\
\text { diversify my vocabulary. }\end{array}$ & & - \\
\hline 75 & $\begin{array}{l}\text { I usually use the words I am } \\
\text { frequently exposed to when writing } \\
\text { or speaking Korean. }\end{array}$ & & $\bullet$ \\
\hline
\end{tabular}




\section{Research procedures}

The participants were asked to answer the questionnaire on-line, and data gathered from the answers were analyzed. The data, which included the category of a strategy used in each question, i.e. the vocabulary discovery strategy or the vocabulary consolidation strategy, were filled in a form of numeric characters instead of written clauses indicating the type of strategies.

The reliability of questions that involved both vocabulary discovery and consolidation strategies was assessed through Cronbach's alpha reliability coefficient. Among the 83 questions in the questionnaire, 55 items concerned the vocabulary discovery strategies and 50 items focused on the vocabulary consolidation strategies. From the analysis, the reliability value for questions concerning the vocabulary discovery strategies was found to be 0.996 while the reliability value of questions regarding the vocabulary consolidation strategies was 0.995 . As the values of both strategy types exceed the statistical acceptability of 0.6 , it can be asserted that the reliability of this questionnaire was relatively high, and its questions were valid to collect the data needed for this research.

Table 3. Reliability level of questionnaire.

Cronbach's alpha Number of questions

\begin{tabular}{lll} 
Vocabulary discovery strategies & .996 & 55 \\
Vocabulary consolidation strategies & .995 & 50 \\
\hline
\end{tabular}

Afterwards, trends in the use of vocabulary learning strategies among students at a Thai university were analyzed. Here, the data were divided into two groups per the two strategy types; that is, a vocabulary discovery strategies group and a vocabulary consolidation strategies group. Analysis at this stage was performed using one-way ANOVA via the SPSS 24 and Excel programs, followed by an investigation into each strategy's frequency of use.

Next, a correlation analysis was conducted using the SPSS 24 program to assess the relationship between the frequency of use regarding vocabulary learning strategies and the students' specific characteristics. 
In this framework, the specific characteristics referred to gender, age, level of Korean language proficiency, experience in residing in Korea, length of Korean language study, experience in traveling/undertaking training in Korea, and the state of being of Korean descent. The means of each strategy's frequency of use were correspondingly utilized in the aforementioned correlation analysis.

\section{RESULTS}

In this research, two research questions were established to be used as guidelines for analysis and discussion.

The first question was: what are trends in Thai university students' use of vocabulary learning strategies (i.e. vocabulary discovery strategies and vocabulary consolidation strategies)?

An analysis on trends in the use of Korean-language vocabulary learning strategies by students at a Thai university performed in this research was focused on whether there were any significant differences between the trend among those using vocabulary discovery strategies and the trend in a group executing vocabulary consolidation strategies.

According to the one-way ANOVA result, no significant difference has been found between the trends of the two groups ( $p$-value was less than 0.05). To ensure high-precision research results, a frequency analysis was also implemented on the Thai students' trends in their use of vocabulary learning strategies, utilizing data gathered from the answers of the 83 questions. Concurrently, K-means cluster analysis was performed in order to identify the most and the least frequently-used vocabulary learning strategies.

Data regarding usage frequency obtained from the 83 questions in the questionnaire were processed to identify the means of each vocabulary learning strategy's usage frequency. Next, the acquired means values were sequenced ranging from the most to the least frequently-used strategy, as shown in Table 4 below.

The result of the K-Means cluster analysis illustrated that there were 45 frequently-used vocabulary learning strategies, the means value of which was 2.68 and above, and 38 seldom-used vocabulary learning strategies. Of the 45 frequently-used strategies, 15 items were classified under the vocabulary discovery strategies; 19 were vocabulary consolidation categories; and 11 belonged to the discovery-consolidation vocabulary strategies. Three most frequently-used strategies as recognized by the students were strategies No. 61: "When I cannot 
recall an exact word while writing or speaking Korean, I refer to the Internet or a dictionary"; No. 25: "When exposed to an unfamiliar word, I look up its meaning in a dictionary"; and No. 43: "I watch Korean TV programs or movies", respectively.

The table below shows an order of the most to the least frequently-used strategies. Each item's strategy type and its usage frequency are also indicated herewith.

Table 4. Usage frequency of each vocabulary learning strategy.

\begin{tabular}{|c|c|c|c|c|c|c|c|c|}
\hline No. & $\begin{array}{c}\text { Strategy } \\
\text { no. }\end{array}$ & $\begin{array}{l}\text { Typ } \\
\text { stra }\end{array}$ & & Means & No. & $\begin{array}{c}\text { Strategy } \\
\text { no. }\end{array}$ & $\begin{array}{l}\text { Typ } \\
\text { stra }\end{array}$ & Means \\
\hline 1 & 61 & & $0^{*}$ & 3.79 & 43 & 15 & & 2.75 \\
\hline 2 & 25 & $\bigcirc^{* *}$ & & 3.67 & 43 & 77 & 0 & 2.75 \\
\hline 3 & 43 & 0 & 0 & 3.51 & 45 & 7 & 0 & 2.68 \\
\hline 4 & 72 & & 0 & 3.49 & 46 & 57 & & 2.62 \\
\hline 5 & 46 & $\bigcirc$ & 0 & 3.40 & 47 & 4 & $\bigcirc$ & 2.60 \\
\hline 6 & 55 & 0 & 0 & 3.38 & 48 & 17 & 0 & 2.59 \\
\hline 7 & 47 & 0 & 0 & 3.35 & 48 & 37 & 0 & 2.59 \\
\hline 8 & 62 & & 0 & 3.21 & 50 & 23 & $\bigcirc$ & 2.57 \\
\hline 8 & 64 & & 0 & 3.21 & 50 & 29 & $\bigcirc$ & 2.57 \\
\hline 8 & 67 & & 0 & 3.21 & 50 & 48 & $\bigcirc$ & 2.57 \\
\hline 11 & 75 & & 0 & 3.19 & 53 & 35 & $\bigcirc$ & 2.54 \\
\hline 12 & 42 & $\bigcirc$ & 0 & 3.17 & 54 & 19 & $\bigcirc$ & 2.52 \\
\hline 12 & 82 & & 0 & 3.17 & 54 & 24 & $\bigcirc$ & 2.52 \\
\hline 14 & 73 & & 0 & 3.14 & 56 & 56 & & 2.49 \\
\hline 14 & 76 & & 0 & 3.14 & 57 & 18 & $\bigcirc$ & 2.46 \\
\hline 16 & 27 & $\bigcirc$ & & 3.13 & 57 & 31 & $\bigcirc$ & 2.46 \\
\hline 17 & 11 & 0 & & 3.11 & 59 & 60 & & 2.44 \\
\hline 18 & 71 & & 0 & 3.05 & 60 & 32 & $\bigcirc$ & 2.41 \\
\hline 18 & 83 & & 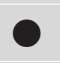 & 3.05 & 61 & 50 & $\bigcirc$ & 2.38 \\
\hline 20 & 8 & $\bigcirc$ & & 3.03 & 61 & 53 & 0 & 2.38 \\
\hline 21 & 49 & $\bigcirc$ & 0 & 3.02 & 63 & 70 & & 2.37 \\
\hline 22 & 2 & 0 & & 2.98 & 64 & 39 & $\bigcirc$ & 2.35 \\
\hline 22 & 68 & & 0 & 2.98 & 65 & 14 & 0 & 2.32 \\
\hline
\end{tabular}

Note: * Vocabulary consolidation category. ** Vocabulary discovery category. 
Table 4. Continued.

\begin{tabular}{cccccccccc}
\hline No. & $\begin{array}{c}\text { Strategy } \\
\text { no. }\end{array}$ & $\begin{array}{c}\text { Type of } \\
\text { strategy }\end{array}$ & Means & No. & $\begin{array}{c}\text { Strategy } \\
\text { no. }\end{array}$ & $\begin{array}{c}\text { Type of } \\
\text { strategy }\end{array}$ & Means \\
\hline 22 & 81 & & $\bullet$ & 2.98 & 66 & 20 & $\bigcirc$ & 2.30 \\
25 & 1 & $\bigcirc$ & & 2.97 & 66 & 26 & $\bigcirc$ & & 2.30 \\
25 & 13 & $\bigcirc$ & & 2.97 & 66 & 36 & $\bigcirc$ & $\bullet$ & 2.30 \\
27 & 79 & & $\bullet$ & 2.95 & 69 & 5 & $\bigcirc$ & & 2.27 \\
28 & 38 & $\bigcirc$ & $\bullet$ & 2.92 & 70 & 45 & $\bigcirc$ & $\bullet$ & 2.22 \\
29 & 9 & $\bigcirc$ & & 2.90 & 71 & 16 & $\bigcirc$ & & 2.19 \\
30 & 10 & $\bigcirc$ & & 2.87 & 71 & 44 & $\bigcirc$ & $\bullet$ & 2.19 \\
30 & 22 & $\bigcirc$ & & 2.87 & 73 & 78 & & $\bullet$ & 2.17 \\
32 & 59 & & $\bullet$ & 2.86 & 74 & 33 & $\bigcirc$ & & 2.11 \\
33 & 30 & $\bigcirc$ & & 2.84 & 74 & 54 & $\bigcirc$ & $\bullet$ & 2.11 \\
33 & 41 & $\bigcirc$ & $\bullet$ & 2.84 & 76 & 28 & $\bigcirc$ & & 2.08 \\
33 & 51 & $\bigcirc$ & $\bullet$ & 2.84 & 77 & 80 & & $\bullet$ & 2.03 \\
36 & 3 & $\bigcirc$ & & 2.83 & 78 & 21 & $\bigcirc$ & & 1.87 \\
37 & 65 & & $\bullet$ & 2.81 & 79 & 12 & $\bigcirc$ & & 1.84 \\
38 & 6 & $\bigcirc$ & & 2.79 & 80 & 69 & & $\bullet$ & 1.81 \\
38 & 40 & 0 & $\bullet$ & 2.79 & 81 & 58 & & $\bullet$ & 1.60 \\
40 & 74 & & $\bullet$ & 2.78 & 82 & 52 & $\bigcirc$ & $\bullet$ & 1.59 \\
41 & 34 & $\bigcirc$ & $\bullet$ & 2.76 & 83 & 66 & & $\bullet$ & 1.54 \\
41 & 63 & & $\bullet$ & 2.76 & & & & \\
\hline
\end{tabular}

The information shown in Table 4 demonstrates that the Thai students employ several, assorted vocabulary learning strategies, both in terms of discovery and consolidation methods, under various circumstances. It has been found that, however, vocabulary consolidation strategies are utilized more extensively than vocabulary discovery strategies. This finding is in line with a research by Lee (2016) noting that foreign students studying the Korean language use diverse methods to learn Korean vocabularies, and they seek to use vocabulary consolidation strategies to a greater extent than using vocabulary discovery strategies. 
The second research question was: do Thai university students' specific characteristics (i.e. gender, age, level of Korean language proficiency, experience in residing in Korea, length of Korean language study, experience in traveling/undertaking training in Korea, and being of Korean descent) have an impact on their use of vocabulary learning strategies?

At this stage, a correlation analysis on Korean vocabulary learning strategies versus the learners' specific characteristics was performed using SPSS 24. This analysis investigated the relationship between the learners' seven specific characteristics (gender, age, level of Korean language proficiency, experience in residing in Korea, length of Korean language study, experience in traveling/undertaking training in Korea, and the state of being of Korean descent), and their vocabulary discovery strategies, vocabulary consolidation strategies and vocabulary discovery-consolidation strategies successively. The acquired result displayed the relationship between the students' specific characteristics and each of the strategy type separately. It was discovered that the correlation was significant at an alpha level of 0.05 , but not at the 0.01 level. For better comprehensibility, an asterisk was marked on the slots showing significance of the correlation coefficient. The following table shows the relationship between the learners' specific characteristics and vocabulary discovery strategies, vocabulary consolidation strategies, and vocabulary discovery-consolidation strategies. From its correlation analysis, there was a significant relationship between the learners' level of Korean language proficiency and vocabulary discovery strategies (Pearson correlation $=0.273$, Significance Probability $=0.030$ ).

Regarding the consolidation strategies, an analysis of data drawn from the answers of the 50 relevant questions revealed that the learners' gender (Pearson correlation $=-0.252$, Significance Probability $=0.047$ ) and the learners' level of Korean language proficiency (Pearson correlation $=0.274$, Significance Probability $=$ 0.030) significantly correlated with vocabulary consolidation strategies.

When analyzing the relationship between the learners' specific characteristics and vocabulary discovery-consolidation strategies using data collected from the answers of all 83 questions, the learners' level of Korean language proficiency was found to significantly correlate with their vocabulary discovery-consolidation strategies (Pearson correlation $=0.283$, Significance Probability $=0.025$ ). 
Table 5. Relationship between learners' specific characteristics and vocabulary discovery strategies, vocabulary consolidation strategies, and vocabulary discovery-consolidation strategies.

\begin{tabular}{|c|c|c|c|c|}
\hline \multirow[t]{2}{*}{$\begin{array}{l}\text { Learners' specific } \\
\text { characteristics }\end{array}$} & $\begin{array}{l}\text { Vocabulary } \\
\text { discovery } \\
\text { strategies }\end{array}$ & $\begin{array}{l}\text { Vocabulary } \\
\text { consolidation } \\
\text { strategies }\end{array}$ & $\begin{array}{c}\text { Vocabulary } \\
\text { discovery - } \\
\text { consolidation } \\
\text { strategies }\end{array}$ & \multirow[t]{2}{*}{$\mathbf{N}$} \\
\hline & \multicolumn{3}{|c|}{$\begin{array}{l}\text { Pearson correlation / Significance Probability } \\
\text { (two-tailed) }\end{array}$} & \\
\hline Gender & $-0.102 / 0.424$ & $-0.252 * / 0.047$ & $0.240 / 0.058$ & 63 \\
\hline Age & $0.033 / 0.800$ & 0.155 / 0.224 & 0.094 / 0.464 & 63 \\
\hline $\begin{array}{l}\text { Level of Korean } \\
\text { language proficiency }\end{array}$ & $0.273^{*} / 0.030$ & $0.274^{*} / 0.030$ & $0.283^{*} / 0.025$ & 63 \\
\hline $\begin{array}{l}\text { Experience in residing } \\
\text { in Korea }\end{array}$ & -0.135 / 0.291 & $-0.160 / 0.209$ & $-0.152 / 0.234$ & 63 \\
\hline $\begin{array}{l}\text { Length of Korean } \\
\text { language study }\end{array}$ & 0.020 / 0.877 & 0.085 / 0.506 & 0.053 / 0.681 & 63 \\
\hline $\begin{array}{l}\text { Experience in } \\
\text { traveling/undertaking } \\
\text { training in Korea }\end{array}$ & $-0.066 / 0.605$ & -0.093 / 0.467 & $-0.082 / 0.523$ & 63 \\
\hline $\begin{array}{l}\text { Being of Korean } \\
\text { descent }\end{array}$ & $0.042 / 0.743$ & -0.007 / 0.954 & 0.019 / 0.881 & 63 \\
\hline
\end{tabular}

\section{CONCLUSION AND DISCUSSION}

From data collection and analysis, it can be seen that the Thai students employ both vocabulary discovery and vocabulary consol idation strategies concurrently, yet they utilize vocabulary consolidation strategies more extensively than vocabulary discovery strategies. The most frequently-used strategy among the students was "If [I] cannot think of certain words when speaking or writing Korean, [I] refer to the Internet or a dictionary".

According to the correlation analysis between the learners' specific characteristics and vocabulary learning strategies, it can be inferred that: 1) the learners' level of Korean language proficiency correlates with their use of vocabulary discovery strategies; 2) the learners' gender and level of Korean language proficiency correlate 
with their use of vocabulary consolidation strategies; and 3) the learners' level of Korean language proficiency correlates with their use of vocabulary discovery-consolidation strategies.

Ultimately, the analysis results demonstrate that the level of Korean language proficiency has an impact on the use of every vocabulary learning strategy, while the learners' gender and level of Korean language proficiency correlate with the use of vocabulary consolidation strategies in particular.

The result of this research greatly contributes to the Korean language vocabulary learning as it is evident that vocabulary consolidation strategies are lucrative and imperative for students' vocabulary learning. Applying vocabulary consolidation strategies in language pedagogy would therefore advance students' vocabulary learning efficacy. On the other hand, it is also important for teachers to familiarize themselves with approaches and strategies that help facilitate students' vocabulary learning and then create responsive activities to encourage students to practice vocabulary usage and boost their language proficiency, especially through writing and speaking.

To date, only a limited amount of study has addressed the relationship between learners' specific characteristics and vocabulary discovery as well as consolidation strategies. This research serves to fill this gap and may therefore be beneficial to Korean language teaching since its findings can be used as a basis for Korean language pedagogy design. Realizing that learners' level of Korean language proficiency contributes to the use of vocabulary learning strategies, teachers should then create vocabulary learning activities that cater to these different levels accordingly. Besides, as age and the level of Korean language proficiency have an impact on vocabulary consolidation strategies, it is suggested that teachers introduce corresponding vocabulary consolidation strategies to students so as to further encourage effective Korean vocabulary learning.

Nevertheless, this research is subject to one limitation: it has yet to substantially propose Korean vocabulary teaching methods that well correspond with learners' specific characteristics. This limitation, however, suggests points to be included in the future research on this topic; that is, further studies are needed in order to explore the use of vocabulary learning strategies among learners of each gender and level of Korean language proficiency. In addition, continuous and comprehensive research regarding vocabulary pedagogy is desirable in order to advance the knowledge in this area. 


\section{REFERENCES}

Baek J.P. (2017). A meta-analysis on the effects of reading strategy instruction in Korean reading education. Bilingual Research, 67, 161-191.

Cohen, A.D., Oxford, R.L. \& Chi, J.C. (2002). Language strategy use inventory. Center for advanced research on language acquisition: University of Minnesota.

Jeon, H.G., \& Kuk, J.S. (2017). A study on aspect of Korean learners' listening strategies use. Korean Education, 110, 281-303.

Kang, B.S. (2013). A study on the education for productive vocabulary improvement (Unpublished doctoral dissertation). Seoul University, Seoul, Republic of Korea.

Kang, K.A., \& Kim, Y.J. (2016). Aspects of Korean intermediate and advanced learners' writing strategy use. Korean Education, 107, 267-295.

Kang, S.H. (1999). Language learning strategies and achievements of Korean language learners. Teaching Korean as a Foreign Language, 23(1), 89-115.

Ki, J.S. (2009). A study of Korean reading strategies employed by Chinese background speakers (Unpublished doctoral dissertation). Sangmyung University, Seoul, Republic of Korea.

Kim, Y.H. (2011). A study on the listening strategy of Korean learners - focusing on the high and low level learners. Eomunyeongu, 69, 5-35.

Kim, Y.J. (2014). A study on reading anxiety and reading strategy use in American college learners of Korean. Teaching Korean as a Foreign Languages, 41, 61-88.

Lee, Y.J. (2016). A study on reading strategy instruction of Korean reading education for academic purposes (Unpublished doctoral dissertation). Sookmyung Women's University, Seoul, Republic of Korea.

. (2017). A study on strategies based instruction method of Korean reading education for academic purposes. Culture and Convergence, 39(2), 31-62.

Lee, Y.R. (2016). A research on the impact of vocabulary study strategy on vocabulary expression ability improvement of Korean language learners (Unpublished doctoral dissertation). Kyunghee University, Seoul, Republic of Korea. 
Lee, Y.R., Kim, I.H., \& Kim, Y.J. (2017). Aspects of strategy use in college language learners of Korean. Foreign Languages Education, 24(4), 277-305.

Ling, S.A. (2016). A study on Korean language learning strategies used by Chinese learners (Unpublished doctoral dissertation). Yeungnam University, Gyeongsan, Republic of Korea.

Oxford, R.I. (1990). Language learning strategies: what every teacher should know. Boston: Heinle \& Heinle.

Sawada, H. (2006). Study on reading strategy use of Japanese KFL learners. Journal of Korean Arts Education Research, 11, 225-254. Schmitt, N. (1997). Vocabulary learning strategies. In N. Schmitt \& McCarthy (Eds.), Vocabulary: Description, acquisition and pedagogy (pp.199-227). Cambridge: Cambridge University Press.

Shin, Y.J. (2016). A research on the strategic approach to the Korean composition of Korean of academic research. Journal of Bangyo Language and Literature, 43, 383-415.

Shon, S.H. (2011). (A) study on language learning strategies of Korean language learners (Unpublished doctoral dissertation). Yonsei University, Seoul, Republic of Korea.

Sim, S.M. (2007). A comparison of reading strategy use between the Japanese and the Chinese background learner in KSL class. Eomunyeongu, 35(1), 441-465.

Sohn, J.R. (2009). The effect of training note-taking strategies on lecture comprehension for learners of Korean for academic purposes. Korean Journal of the Applied Linguistics, 25(1), 1-26.

Wang, D. (2008). A study on communication strategies in spoken Korean teaching. Journal of Korean Culture, 11, 75-102.

Won, M.J. (2010). Comparing the use of language learning strategies. Korean Language and Literature in International Context, 48, 277-313.

Yun, J.K. (2013). The effects of Korean knowledge and listening strategy on listening comprehension. Eomunyeongu, 78, 37-58. 